\title{
CRISTIANO DE ALÁ, RENEGADO DE CRISTO. EL CASO DE ABDALLA, FILL D'EN DOMINGO VALLÉS, UN VALENCIANO AL SERVICIO DEL ISLAM
}

\author{
José Vicente Cabezuelo Pliego*
}

\section{UNA HISTORIA DE RENEGADOS}

Durante toda la Edad Media hispana las relaciones Islam-Cristiandad se vieron mediatizadas jurídicamente, en opinión certera de Ch.E. Dufourcq, por la guerra, de no mediar paz o tregua entre los contendientes ${ }^{1}$. No obstante, a pesar de esta situación general de hostilidad bélico-religiosa, muy particular en el reino de Valencia ${ }^{2}$, quedaron tendidos puentes de conexión entre uno y otro colectivo, y no ya tanto de entendimiento político o económico, sino incluso religioso. Entendimiento, acercamiento último que derivó en una aceptación mutua; convivencia real y efectiva más o menos pacífica en aquellos espacios en que cohabitaban elementos de las dos comunidades, al tiempo que, aunque de modo más excepcional -quizá menos de lo que pensamos- en un intercambio de creyentes, de personas físicas que conseguían salvar los muros de la intolerancia para ingresar y engrosar las filas de la creencia que hasta esos instantes se consideraba errónea.

* Universidad de Alicante.

1. Ch.E. DuFourCe, L'expansió catalana a la Mediterrània Occidental. Segles XIII $i$ XIV, Barcelona, 1969, p. 57. Es traducción del original francés titulado L'Espagne Catalane et le Maghrib aux XIIl et XIV siècles. De la bataille de las Navas de Tolosa (1212) à l'avènement du sultan mérinide Abou-l-Hasan (1331), París, 1966. Cf. también del mismo autor «Chrétiens et musulmans durant les derniers siècles du Moyen Âge», en La península ibérica y el Mediterráneo centro-occidental (siglos XII-XV), Barcelona, 1980, pp. 207-225.

2. Cf. R.I. BuRns, «Avalots socials a la València del segle XIII», en Jaume I $i$ els valencians del segle XIII, Valencia, 1981, pp. 269-300. Traducción al catalán de «Social riots on the christianmoslem frontier (thirteenth-century)», en American Historical Review, 66, 1961, pp. 378-400. 
El cambio de fe, voluntario -se entiende-, como ha expuesto J. García Antón ${ }^{3}$, siguiendo entre otros a J. de Mata Carriazo y a J. Torres Fontes, fue un fenómeno particularmente vivo en el paisaje social de la frontera, donde por motivaciones distintas gentes de uno y otro lado se entrecruzaban dando lugar a "tornadizos" y "renegados".

De las dos situaciones expuestas, la que más interesa a nuestro estudio es la generada por los apóstatas o renegados, aquellos que abandonan la fe de Cristo para abrazar el Islam. El renegado cristiano es una figura escasamente documentada a lo largo de la Historia. Y sin embargo no por ello desconocida. Este "extraño silencio", tal y como lo denominan Bartolomé y Lucille Bennassar, no es tan extraño, pues como ellos mismos afirman se ha debido fundamentalmente a la escasez de evidencias documentales, nunca de noticias sobre su existencia ${ }^{4}$. Si bien, es cierto que tales evidencias son. más numerosas para la época moderna que para la medieval, como han puesto de relieve los citados autores en una espléndida monografía sobre el tema en cuestión, así como también E. Solá ${ }^{5}$ o yendo un poco más lejos el célebre F. Braudel ${ }^{6}$.

Los siglos bajomedievales hispanos, aquellos en los que el Islam estaba a la vuelta de la esquina, contaron también -posiblemente con más- con gentes que desde la Cristiandad se refugiaban en el Islam, nazarí o norteafricano $^{7}$. Bien espontáneamente, bien primero forzados por unas circunstancias asumidas a posteriori, numerosos nacidos bajo el signo de la cruz en un momento de su vida cambiaron éste por el de la media luna. Motivaciones diversas fueron/serían las que barajaron/barajarían cada uno de ellos, pues condiciones socioeconómicas diversas disfrutaban/disfrutarían. De este modo, nos encontramos desde el singular caso de un clérigo, como el franciscano mallorquín Anselm Turmeda, que abraza la fe de Mahoma tras un estudio teológico comparado de las dos religiones ${ }^{8}$, hasta otros, que lo harían

3. J. GARCÍA ANTÓN, «La tolerancia religiosa en la frontera de Murcia y Granada en los últimos tiempos del reino nazarì, en Murgetana, LVII, Murcia, 1980, pp. 133-143.

4. B. BenNASSAR y L. BenNASSAR, Los cristianos de Alá. La fascinante aventura de los renegados, Madrid, 1989, pp. 11-12.

5. E. SOLA, Un Mediterráneo de piratas: corsarios, renegados y cautivos, Madrid, 1988.

6. F. BRAUDEL, El Mediterráneo y el mundo mediterráneo en la época de Felipe II, México, 1953, II, pp. 97-124.

7. Giménez Soler menciona que a principios del siglo XIV la población del reino de Granada estaba constituida en buena parte por renegados y descendientes de renegados, cifrando incluso en cincuenta mil el número de éstos que allí residían. A. GIMENEZ SOLER, La Corona de Aragón y Granada.

Citado por M. ${ }^{a}$ T. FERRER I MALlol, Els sarraïns de la Corona catalano aragonesa en el segle XIV. Segregació i discriminació, Barcelona, 1987, pp. 78-79.

8. M. de Epalza FERrer, Fray Anselm Turmeda (Abdalläh Al-Taryumān) y su polémica islamo-cristiana (edición, traducción y estudio de la Tuhfa), Madrid, 1993. 
siguiendo motivaciones más prosaicas aunque siempre de forma voluntaria. J. García Antón ofrece algunos casos de individuos, hombres y mujeres, que voluntariamente cruzan la "frontera" para abrazar el Islam". De igual modo $M .{ }^{2}$ T. Ferrer refiere la existencia de renegados que por motivos desconocidos abandonan sus haciendas para vivir plenamente como musulmanes ${ }^{10}$, siendo raros los casos en que se conocen los móviles, como el sentimental, que resalta en el de la viuda Elvira, vecina de Catral, en la Procuración de Orihuela, y amante de un mudéjar crevillentino, que abandonó sus bienes, huyó a Granada y abjuró de su fe cristiana junto con sus hijas ${ }^{11}$, así como quizá el que refiere J.A. Barrio en esta misma publicación de una joven cristiana de Monforte raptada por un grupo de musulmanes convecinos y llevada a "tierra de moros", donde la tal cristiana abrazó el Islam de forma voluntaria, hecho que causó gran consternación en las autoridades alicantinas al considerarlo un ejemplo pernicioso y peligroso para la ciudadanía, al poder ser utilizado por el colectivo musulmán valenciano como una victoria sobre el mundo cristiano ${ }^{12}$; al tiempo que quienes huían para evitar la acción de la justicia ${ }^{13}$. Si bien, quizá el motivo principal de conversión por parte de los cristianos fuese la conveniencia, cuando se veían presos de granadinos o norteafricanos, con el único fin de salvar el duro cautiverio. Así como igualmente las presiones de sus captores, quienes quizá también -en algún momento- ofreciesen a sus víctimas la conversión como el único medio para seguir vivos o conservar todos sus miembros ${ }^{14}$. Este tipo de reniego es denominado por Bennassar "de boca"15.

Renegar de Cristo, de la Iglesia, de la autoridad, de la familia y vincularse al enemigo para ser uno más, y todo ello de forma consciente, era un viaje sin retorno. De regresar y ser descubierto ... el escarnio público, la tortura y la hoguera ${ }^{16}$.

9. J. GARĆ́A ANTÓN, «La tolerancia religiosa ...», pp. 136-140.

10. M. T. FeRrer I MALLOL, Els sarraïns de la Corona catalano aragonesa ...., p. 80.

11. Ibidem, pp. 37-38 y 80 .

12. J.A. BARRIO BARRIO, «La difícil convivencia entre cristianos y musulmanes en un territorio fronterizo. La Gobernación de Orihuela en el siglo XV», en Sharq al-Andalus. Estudios Mudéjares y Moriscos, 13 (en prensa).

13. J. TORRES FONTES, «La actividad bélica granadina en la frontera murciana (ss. XIII-XV)», en Principe de Viana, XLVII, anejo 3, Homenaje a José María Lacarra, Pamplona, 1986, p. 736.

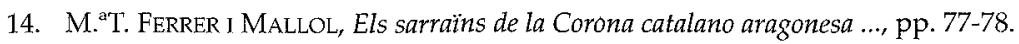

15. B. BENNASSAR, «La vida de los renegados españoles y portugueses en Fez (Hacia 15801615)», en Actas del Coloquio Relaciones de la peninsula ibérica con el Magreb (siglos XIII-XVI), Madrid, 1988, p. 671.

16. "Heretges e sodomites sien cremats. E si crestia eligira lig de iuheus o de sarrahins, ço es ques fara iuheu o serrahi, e per ço sera circuncidat, sia cremat". Furs e Ordinations fetes per los gloriosos reis d'Aragó als regnícoles del Regne de València, Valencia, Imprenta de Lamberto Palmart, 1482, ed. facsímil, Universidad de Valencia, 1977, Libre IX, rúb. VI, XXVIII, p. 163. 
En este trabajo pretendemos mostrar la historia singular -en cuanto a única, personal-, la peripecia vital de un cristiano valenciano que a mediados de la segunda década del siglo XIV, en un mundo -su propia tierra- de marcado fervor antiislámico, de segregación y discriminación hacia el elemento musulmán convecino ${ }^{17}$, abandonó la seguridad de su casa, de su familia, para, consciente o inconscientemente, vivir una aventura que, seguramente, le terminó reportando una muerte cruel que, por otro lado, le permitió entrar como mártir en el paraíso prometido a todo fiel musulmán. Es el caso de Abdalla/Andreu, fill d'En Domingo Vallés, cristiano de Alá, renegado de Cristo.

\section{RIDWAN}

Durante el primer tercio del siglo XIV las relaciones entre la Corona de Aragón y Granada habían sido muy fluctuantes, intercalándose períodos de tensa paz, de tregua y de abierta hostilidad; ello además de la continua presencia a un lado y a otro de la frontera de incontrolados almogávares que peinaban los campos en busca de ganados y pastores, campesinos y viandantes que asaltar y raptar ${ }^{18}$. Jaime II mantuvo hasta su muerte, en 1327, esta política conciliadora y disuasoria con Granada, pero su hijo y sucesor, Alfonso IV, en colaboración con Alfonso XI de Castilla, orientó la estrategia cristiana claramente hacia la guerra. Con apoyo del papado, tanto político como económico, las potencias hispanas planearon una guerra total contra el reino nazarí de Granada, una Cruzada contra el Islam andalusí. Si bien todo quedó en agua de borrajas cuando el castellano abandonó la empresa en 1331 conformándose con haber obtenido algunos castillos en la frontera. Alfonso el Benigno quedó solo frente al enemigo granadino ${ }^{19}$.

17. Consúltese el magnífico trabajo de M. T. FERrer I MALlol, Els sarraïns de la Corona catalano aragonesa...

18. M.T. FERRER I MALLOL, La frontera amb l'Islam en el segle XIV. Cristians $i$ sarraïns al País Valencià, Barcelona, 1988, pp. 47-125. Centrado en la primera década del siglo XIV, J.V. CABEzuelo Pliego, «Procuración, frontera y organización defensiva del reino de Valencia frente al Islam a principios del siglo XIV. Gombau d'Entença y Granada», en Actas del Congreso La frontera oriental nazari como sujeto histórico, en prensa. Aunque más genérico, resulta de gran interés el trabajo de J. TORRES Fonr'es, «La actividad bélica granadina...», pp. $735-736$.

19. Cf. J. de Zurita, Anales de la Corona de Aragón, edición preparada por A. CANELLAS LÓPEZ, Zaragoza, 1972, 3, VII, VII, pp. 323-324. A. GIMENEZ SOLER, Don Juan Manuel. Biografía y estudio crítico, Zaragoza, 1932, pp. 95-98. M. SANCHEZ MARTiNEZ, «La contribución valenciana a la cruzada granadina de Alfonso IV de Aragón (1327-1336)", en Primer Congreso de

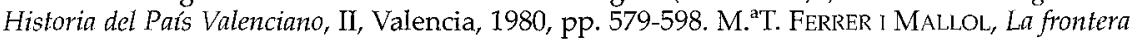
amb l'Islam..., pp. 125-127. M.A. MANZANO RODRIGUEZ, La intervención de los benimerines en la península ibérica, Madrid, 1992, pp. 220-223. Lamentamos no haber podido utilizar el trabajo de A. Giménez Soler titulado La Corona de Aragón y Granada, así como especialmente la Tesis Doctoral de M. Sánchez Martínez, con el mismo título que el trabajo citado anteriormente, quien ha estudiado con todo lujo de detalle este asunto. 
La respuesta de los granadinos no se hizo esperar. En octubre de ese año un cuerpo de ejército nazari, capitaneado por el caudillo Ridwan, penetró en territorio valenciano. El objetivo era Guardamar, en la desembocadura del Segura, plaza que fue totalmente derruida y su población cautivada ${ }^{20}$. En su marcha de vuelta hacia Granada los invasores arrasaron las tierras del Vinalopó Sur y del Segura, destruyendo campos de cultivo, estructuras de regadío y llevándose consigo gran número de animales, cereales, cautivos y de población autóctona procedente de Elche, Crevillente y del valle de Elda que voluntariamente se unió al grupo ${ }^{21}$. La elección del objetivo y del momento fueron precisas. La fragilidad de las defensas de Guardamar auguraba un éxito seguro ${ }^{22}$, mientras que la no presencia del procurador de Orihuela en el territorio, no sabemos si conocida o no por los granadinos, impedía una acción militar conjuntada ${ }^{23}$. Pero quizá lo fundamental fue lo sigiloso y rápido de la entrada, evitando los sistemas de información cristianos, tanto en Granada como en la propia frontera. Toda la Procuración de Orihuela estuvo "en grande peligro de perderse", peligro, en palabras de Zurita, por "la furia de los moros y el descuido que hubo en proveer de gente aquella frontera teniéndose por rompida la guerra con el rey de Granada" 24 .

20. Zurita señala que tras la toma de Guardamar, Ridwan envió mensajeros al Concejo de Murcia ofreciendo la plaza al rey de Castilla. J. de ZuRrTA, Anales..., 3, VII, XV, p. 348.

21. Ibidem, Libro VII, XV. P. BELLOT, Anales de Orihuela (Siglos XIV-XVI). Estudio, edición y notas a cargo del Dr. Juan TORRES FONTES, Orihuela, 1954-1956, I, pp. 16-17 y II, p. 177. M. aT. FERRER I MALLOL, La frontera amb l'Tslam..., pp. 127-131 y doc. n." 54. M. SÁNCHE'Z MARTínEZ, «Sobre la fiscalidad real en el reino de Aragón durante el primer tercio del siglo XIV: los subsidios para la campaña granadina (1329-1335)», en Revista de Historia Jerónimo Zurita, 6768, Zaragoza, 1994, doc. n. 2 2. J.V. CABEZuelo PleGo, Poder público y administración territorial en el reino de Valencia, 1239-1348. El oficio de la Procuración, en prensa.

22. Cf. M. ${ }^{a}$ T. FERRER I MALLOL, «La tinença a costum d'Espanya en els castells de la frontera meridional valenciana (segle XIV)», en Miscel-lània de Textos Medievals, 4, Barcelona, 1988, pp. 1-102. Id., «La frontera meridional valenciana durant la guerra amb Castella dita dels dos Peres», en Pere el Cerimoniós i la seva època, Barcelona, 1989, pp. 261, 264-265, 277-278, 291292. J.V. Cabezuelo Pliego, La guerra de los dos Pedros en las tierras alicantinas, Alicante, 1991, pp. 54, 63-64, 80-81. J. HinOJOSA MONTALVO, «Guardamar: un castillo en ruinas a fines de la Edad Media», en Castells, 6, Alicante, 1996, pp. 19-22.

23. Jofre Gilabert de Cruilles, procurador de Orihuela, y el procurador de Valencia, Jaime de Jérica, se encontraban por entonces en Valencia inmersos en las nupcias de Pedro de Jérica y de Buenaventura de Arborea. J. de ZURIrA, Anales..., 3, Libro, VII, XV, p. 347. Aunque Bellot señala que la ausencia de Jofre Gilabert de Cruillles de las tierras oriolanas se debió a que fue llamado a la Corte por la reina (p. 348). P. Bellot, Anales de Orihuela..., I, p. 16. M. 'T. FERRER I MALlol, La frontera amb l'Islain..., p. 127. Id., Organització $i$ defensa..., p. 118. J.V. CABEzuelo Plieco, «De nuevo sobre Procuración, frontera y organización defensiva del reino de Valencia frente al Islam en el siglo XIV: Jaime de Jérica y Granada», en $V$ Jornadas de Historia Militar. El Mediterráneo: hechos de relevancia histórico-militar y sus repercusiones en España, Sevilla, 1995, en prensa. Id., Poder público y administración territorial...

24. J. de Zuri'TA, Anales..., 3, VII, XV, p. 348. 
Las tropas de Ridwan se retiraron a sus bases, en la frontera de Vera, mientras que el caudillo corrió a Granada a ofrecer el botín a Muhammad IV. Mientras, en tierras valencianas se iniciaron los preparativos para la defensa -fortificaciones, viandas, hombres, sistemas de comunicación y espionaje, etc.- porque las noticias que llegaban hablaban de otro inminente ataque; el espacio de la Procuración oriolana volvía a aparecer de nuevo como blanco de los granadinos y el nombre que más se repetía era Alicante, villa de cuya defensa pasó a ocuparse personalmente el procurador del territorio ${ }^{25}$.

Se esperó durante todo ese invierno la tan temida entrada de Ridwan, pero ésta llegó en la primavera de 1332. A pesar de las precauciones defensivas cristianas, no sirvieron ni puestos de vigilancia ni espías cuando de nuevo el caudillo granadino entró en tierras oriolanas sin ser visto ni oído al frente de una importante hueste y puso sitio a la villa de Elche. A todos cogió por sorpresa la presencia del enemigo, por otra parte "esperada", que al no lograr doblegar por la fuerza las férreas defensas de los ilicitanos regresó a Granada. Si bien, no todos regresaron. Algunos servidores de Ridwan quedaron en los dominios del rey de Aragón con misiones que cumplir. Uno de ellos fue localizado y capturado en Alicante. Sus declaraciones fueron sorprendentes.

\section{LA CAPTURA DE ABDALLA/ANDREU: UN PRIMER INTERROGATORIO VOLUNTARIO}

Un miércoles, 15 de abril de 1332, la autoridad alicantina competente, el justicia de la villa Pere Sepulcre, decidió tomar declaración a un musulmán detenido, al que en buena lógica se le consideraba de antemano espía granadino por las vestiduras que portaba. Junto al justicia estaban presentes fray Guillem de Guimerà, lugarteniente del castellano de Amposta, fray Bernat de Monsonís, comendador mayor y lugarteniente del maestre de Montesa, fray Dalmau de Cruilles, lugarteniente de Jofre Gilabert de Cruilles, procurador de Orihuela, así como los jurados y algunos prohombres de la villa alicantina ávidos de conocer el porqué de la presencia de un huésped tan incómodo ${ }^{26}$. Hasta ese momento todo serían especulaciones en Alicante sobre el reo; tan sólo se sabía su nombre, Abdalla, que había llegado con la tropa granadina que esos días había asediado Elche y que por razones desconocidas se encontraba en Alicante. Los inquisidores lo querían saber todo acerca del prisionero, fundamentalmente las razones por las cuales se había aparta-

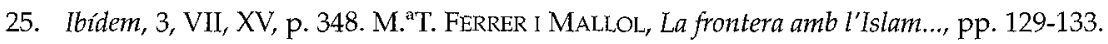

26. ACA, C, processos en quart, 1332. La localización de este proceso la debemos a Jaume Riera, del Archivo de la Corona de Aragón, a quien le agradecemos la gentileza de habérnoslo ofrecido. 
do del grueso del ejército nazarí y presentado en las playas alicantinas. ¿Huía o espiaba? eran las opciones que se barajaban; la primera por Abdalla, la segunda por sus captores. De ellas dependía el veredicto.

El cautivo se presentó con el nombre de Abdalla, aunque se anunció cristiano de nacimiento al declarar que su padre, de nombre Domingo Vallés, era vecino de Museros, localidad situada en la huerta de Valencia en la que él también había nacido. Quiso entonces voluntariamente prestar declaración a todo aquello que quienes le interrogaban quisiesen saber y empleando la costumbre islámica, válida por otro lado cuando quien la daba era musulmán, juró por la alquibla decir la verdad.

Abdalla inició su declaración señalando que en junio - a la festa de sent Johan- haría dieciocho años que había salido de su Museros natal, para posteriormente contar la peripecia de su vida durante ese largo tiempo. De Museros, según contó, pasó por mar a Fez junto con un compañero de viaje llamado Ramón Mirambell. Sin indicar las razones de su visita al norte de África, entre otras cosas porque no se le preguntaron, dijo haber permanecido con el citado Mirambell en Fez por espacio de un año, poch mes o menys, de quien después se separó para vivir con otro hombre, de nombre Pero Ximénez, durante tres meses. Transcurrido ese tiempo Ximénez y él marcharon a Marruecos, si bien a su llegada el sultán marroquí "maztotà et fou maztotà a ell et a altres, et per rahò del dit maztotament" fue a parar a Sigilmasa, adonde residió durante cuatro años. El oasis de Sigilmasa era un importante centro caravanero situado al SE de Marrakech, a los pies del Átlas y del Sahara, en la ruta que ponía en comunicación el norte de Marruecos con el África Negra ${ }^{27}$. En el dicho lugar fon tallat-circuncidadojunto con otros mil doscientos cristianos, según sus cuentas, lógicamente cautivos como él. En ese acto perdió su nombre cristiano, Andreu, Andreu Vallés, y tomó el gentilicio islámico de Abdalla, que quiere decir siervo de Dios, nombre que en ningún momento eligió él, sino que se le adjudicó por voluntad del sultán, para abrazar una nueva fe, la de Mahoma. Recordaba que el hecho, su conversión forzada, se produjo un día jueves en ora de misses. Se le preguntó entonces cuánto tiempo hacía que se había convertido al Islam, a lo que Abdalla contestó que no recordaba exactamente el año, pero que había sido en el tiempo en que los infantes castellanos Pedro y Juan atacaron la vega de Granada, donde encontraron la muerte, lo que ocurrió en la primavera de $1319^{28}$.

27. Obsérvese la ubicación de Sigilmasa en W.C. BRICE, An Historical Atlas of Islam, Leiden, 1981, pp. 40-41.

28. J. de Zurita, Anales..., 3, VI, XXXIV, pp. 129-130. M. ${ }^{a}$ T. Ferrer i Mallol, La frontera amb l'Islam..., p. 116. J.V. CABEZUelo Pliego, Poder público y administración territorial... 
Ya como musulmán permaneció Abdalla en Sigilmasa por espacio de dos años, de donde pasó a Tremecén. No señaló el tiempo que vivió en esta ciudad norteafricana, pero sí que allí conoció y trató con un personaje, de su misma nueva fe, con el que quizá le uniesen más vínculos que el meramente religioso. Su nombre era Amer Alcalpí y su profesión patrón de un barco, gentilicio desde luego vinculado con sus añoradas tierras del Sharq alAndalus, de su Valencia natal. Tras su encuentro debieron compartir recuerdos del lejano hogar. Fuese como fuese, Abdalla decidió regresar con su nuevo amigo a la península, desembarcando en Almería. En ningún momento se señala la dedicación profesional de Alcalpí. ¿Comerciante? ¿pescador como lo eran muchos de los moros de Calpe? No lo creemos. Parece más verosímil pensar que se dedicase a actividades piráticas en la zona del mar de Alborán, y no ya sólo porque Abdalla no mencione su profesión queriendo quizá evitar cualquier relación con alguien que practicaba el corso, sino fundamentalmente porque apunta que patroneaba un leny de moros, un leño, embarcación ligera de cabotaje utilizada tanto en el transporte de mercancías como para la guerra ${ }^{29}$, siendo muy posible que estuviese armada si había de navegar por las aguas de la zona del Estrecho ${ }^{30}$.

Nuestro protagonista arribó a Almería, el principal puerto granadino, como musulmán, aunque siempre con la intención de regresar a su tierra, a su casa, como cristiano. La estrategia a seguir para lograr su objetivo era incorporarse a alguna hueste que se dirigiera contra la cristiandad hispana y escapar ya en espacio enemigo, por ello se unió al ejército nazarí que asedió Elche a principios de la década de 1330 y por ello su presencia en las playas alicantinas, ya como huido.

Lo cierto es que entre su llegada a Almería y su presencia en Alicante transcurrieron varios años, muchos, veremos. Abdalla abandonó a Alcalpí y se dirigió hacia la capital granadina, adonde llegaría según su relato hacia 1324, para desde allí escapar a terra de christians. Pero hasta que eso se produjo hubieron de transcurrir ocho años. Llegados a este punto la pregunta de quienes le interrogaban no había de ser otra que ¿por qué tanto tiempo en Granada? ¿no podía haber intentado la huida antes? Aquí el relato comenzó a mostrarse incoherente y a hacer dudar a sus oyentes de su veracidad. Hasta ese momento Abdalla/Andreu se había presentado como un hombre libre, un ciudadano musulmán, que tras haberse convertido al Islam, haberse circuncidado, había viajado libremente por el norte de África y arribado a

29. A. Garcí Sanz, Història de la Marina Catalana, Barcelona, 1977, p. 70. J. Hinojosa MonTALVO, «Armamento de naves y comercio con el reino de Granada a principios del siglo XV», en V Coloquio de Historia Medieval de Andalucía, Córdoba, 1988, p. 652.

30. Pese a que en los avistamientos valencianos durante el siglo XIV no sea la nave más empleada por el corso musulmán. Cf. A. DIAZZ BORRAs, Los origenes de la piratería islámica en Valencia. La ofension musulmana trecentista y la reacción cristiana, Barcelona, 1993, pp. 63-78. 
Granada. ¿Por qué entonces no prosiguió viaje? Parece lógico pensar que su condición de renegado levantase muchas sospechas y que por cautela habia que esperar el momento propicio. Pero ocho años eran, posiblemente, demasiado. Abdalla lo justificó señalando que a su llegada a la capital nazarí fue hecho esclavo por el rey granadino, quien lo tuvo pres et ferrat el nas, pres continuament per temps de VIII anys. Las razones de su nuevo apresamiento, afirmó, se debieron a su condición de "cristiano", motivo por el cual no contó con licencia para salir de la ciudad durante los años en que residió en ella. Fueron tiempos muy duros, relató Abdalla, pues hubo de trabajar -obrava et laurava- en el campo y en la construcción junto al resto de cautivos cristianos al servicio del rey. Años duros durante los cuales jamás reivindicó su condición de musulmán que le hubiera liberado de inmediato de tan ignominiosos y pesados quehaceres. Tan sólo al final de su cautiverio, en los últimos veinte días, se anunció como seguidor del Profeta, fon atrobat moro según sus palabras -el conocimiento del rito islámico y su circuncisión habían de ser muestras palpables de su fe musulmana-, et per aquesta rahó lo trageron de les ferres et de les presons. Abdalla no señaló en ningún momento las motivaciones de su inminente cambio de parecer, pero sí dijo a sus carceleros que ingresó de inmediato en el ejército que el rey granadino preparaba contra el reino de Valencia. Parece evidente que lo que el de Museros quiso apuntar es que la preparación de esa campaña contra Alfonso el Benigno era la ocasión que había esperado tanto tiempo para regresar a su patria y volver a abrazar la fe de Cristo, siendo esa la única razón por la que se declaró musulmán. Su anhelo, pasados dieciocho años, se veía doblemente cumplido, pues de la mano de Ridwan no sólo regresaría a terra de christians ... com christià, sino que directamente lo haría al reino de Valencia, muy cerca de su hogar.

Formó entonces parte del ejército con el que el caudillo Ridwan cruzó el despoblado reino de Murcia y puso sitio a la villa de Elche en la primavera de 1332. Los inquisidores preguntaron a Abdalla si mientras actuó como integrante de esa hueste hizo vida como musulmán, es decir, si meniava carn et fahía la calà, a lo que contestó que no. El hecho de practicar la calà le hubiese delatado enseguida ante sus jueces, pero no entendemos por qué se le preguntó si comía carne. Quizá se debiese a que por entonces los cristianos estaban en Cuaresma, siendo precisamente ese mismo día 15 miércoles santo; es decir, el preso había sido capturado en la misma semana de la pasión y muerte de Jesús en la Cruz, con lo que los ánimos estarían ciertamente encendidos caso que se demostrase que era un impostor, un renegado. Pero lo cierto es que, ¿iba Andreu a recordar después de casi dos décadas de vida con infieles que en esos días se celebraba la Cuaresma? Desde luego parece inverosímil que lo hiciese, a no ser que alguno de sus captores se lo hiciese saber, después de algún insulto, y/o viese durante el viaje que le llevó hasta la celda alicantina en que moraba signos que trajesen a su memoria recuerdos de lejanas Semanas Santas en Museros; o bien estuviese dentro de la estrategia militar granadina atacar el reino de Valencia de nuevo en Semana Santa. 
Llegados a este punto Abdalla relató la forma en que escapó. El asedio a Elche era la situación perfecta. Nadie estaría pendiente de él. Nadie estaría pendiente de nadie nada más que de los que estaban tras las murallas que se querían sobrepasar. Idas, venidas, gritos..., un vaivén de gentes hacia todas partes, de animales, de máquinas de guerra. No habría otro momento más adecuado, con lo que ¡ahora o nunca! debió decirse Abdalla. Entonces, en medio de todo el barullo se separó del grupo y se ocultó en una acequia, donde permaneció inmóvil hasta que comenzó a oscurecer. La noche, pensó, había de ser su aliada. Y asi fue, a la caída de la tarde, com fou vespre, huyó hacia el este, hacia el mar, por el cami tro al Cap del Aljub, dejando a izquierda y derecha huertas, pequeños palmerales disemimados, almendros, olivos y campos de tamarindo, ginesta, esparto, junco, carrizo y salicor salpicados por la flor amarilla de la olivarda. El episodio de la huida ocurría el lunes 13 de abril. Las horas de la noche del lunes al martes Abdalla las pasó corriendo y ocultándose hasta que al amanecer alcanzó la línea de costa de Santa Pola actual, el puerto medieval de Elche ${ }^{31}$. La suerte estaba de su lado, pues encontró amarrada en la orilla un leut de pexcar amb IIIes hòmens, con el que llegó hasta Alicante, donde fue capturado y encarcelado. Suerte por hallar una embarcación, y más suerte aún porque ninguno de los hombres que la vigilaban pudiesen evitar su marcha, pues el prisionero señaló que nadie hizo nada por capturarle o impedir que tomase la barcaza y ell s'entrà dins lo dit leut per son plan alt. Ésta es la historia que relató a sus inquisidores Andreu Vallés, Abdalla durante los anteriores tres lustros.

Sus captores, aquellos que debían verificar la autenticidad de los hechos, se encontraban ante una difícil situación, ante un dilema. Frente a ellos se mostraba la contradicción: el espíritu del martirio de Cristo en la persona de un sarraceno, o al menos de alguien que vestía, calzaba, peinaba y portaba en su cuerpo los estigmas del Islam. Se le preguntó, entonces, por eso mismo, por el cuidado de su pelo y de su barba, típicamente musulmanas, a lo que él respondió que s'alhenyà los cabells del cap et de la barba... a la rahó que'l desferraren. ¡Pero hacía tan poco tiempo de eso! Se le preguntó de nuevo si durante el tiempo en que estuvo en Elche invocó el nombre de Mahoma y si entró en combate, respondiendo obviamente que no. Una respuesta afirmativa a tales cuestiones y hubiese firmado su sentencia de muerte. Así como, finalmente, si sabía alguna cosa al respecto de tratos entre los mudéjares de Elche o del país y los granadinos. La respuesta fue tajante, pues apuntó que desde luego esos tratos habían existido, hasta el punto que los mudéjares ilicitanos y crevillentinos se habían mostrado como quinta columna de los nazaríes en el reino de Valencia y que al temer que esa conexión pudiese ser co-

31. A. Ramos Folques, Santa Pola y su historia, Alicante, 1974. J. Hinojosa Montalvo, «El "Cap del Aljup", puerto medieval de Elche», en Mayurqa, 23, Homenatge a Álvaro Santamaría, 1989, I, pp. 311-324. 
nocida por las autoridades cristianas muchos musulmanes avecindados en Elche y Crevillente huyeron a Granada con todo aquello que pudieron portar consigo.

\section{LA ASUNCIÓN DEL DELITO: UN SEGUNDO INTERROGATORIO}

\section{AB TURMENT}

Lo cierto es que las autoridades cristianas no quedaron satisfechas con esta declaración, pese a que el prisionero contestó a todas las cuestiones que se le plantearon. Muchas fueron las dudas que suscitó el testimonio de Abdalla/Andreu, pero más fueron las contradicciones, que lógicamente no cayeron en saco roto. ¿Por qué se marchó, sin motivo aparente, a "tierra de moros"? ¿Por qué se mostró en Granada como cristiano cuando lo lógico hubiera sido lo contrario? ¿Acaso quería aparecer como mártir a los ojos de sus carceleros? ¿Cómo pudo evadirse de cumplir sus obligaciones como musulmán durante el asedio de Elche ante tantos ojos que le sabían renegado? ¿Acaso no hubiese tenido que demostrar su fe con más convicción que los demás para huir de murmuraciones? Si durante toda su estancia en Granada vivió como esclavo cristiano y sólo al final reivindicó su condición de musulmán ¿cómo tenía tan cuidado el cabello y tan crecida la barba? ¿Cómo pudo sorprender a tres hombres y arrebatarles una barca? En definitiva, ¿llegó a Alicante huyendo del Islam o para espiar al enemigo y/o dar aviso a sus correligionarios de lo que ocurría unas leguas al sur? ¿Mártir o renegado? ¿Volvía a la fe que nunca abandonó o había hecho apostasía de ella? Eran las cuestiones que bullían en las mentes y también, seguro que sí, en los labios de quienes tenían la obligación de conocerlas.

De todos modos, la situación no era la más adecuada para Abdalla. Semana Santa en una villa de frontera con el enemigo, infiel para más señas, tocando a sus puertas por tierra y por mar y un prisionero acusado de espionaje. Un solo cabo suelto condenaría a muerte al prisionero. Bartolomé y Lucille Bennassar apuntan acertadamente que "en todo proceso de renegados, en cuanto las declaraciones del acusado despiertan sospechas, los jueces persiguen obstinadamente «la intención», es decir, la confesión de la creencia en la posibilidad de salvarse en la religión de Mahoma, en que la fe del profeta es «buena» y en que las abluciones del guadoc purifican cuerpos y almas"32. Pero aquí, además de eso, había más, mucho más. Estaba en juego la integridad territorial del reino de Valencia.

Los testimonios de Abdalla fueron analizados en profundidad por sus captores y en ellos se halló al testigo vari e discordant. Por tal razón el justicia

32. B. Bennassar y L. Bennassar, Los cristianos de Alá..., p. 54. 
alicantino ordenó una nueva confesión, pero en esta ocasión ab turment, per tal que de la sua boca fos sabuda la veritat del feyt ${ }^{33}$. El castigo físico mudaría el parecer de quien se creía mentía, o bien sufriéndolo se afianzaría la verdad de sus palabras. Se dispuso entonces que fos pinat para aplicársele dolor, seguramente a través del látigo. Pero Abdalla no debía ser un hombre con voluntad de hierro y quizá antes de que el cuero estallase contra el viento, ya no contra su piel, pidió que n'ol pegasen, que diría la veritat. Es posible que en este mismo instante, sin saberlo, estuviese declarándose culpable.

Se le preguntó si su conversión al Islam había sido voluntaria o forzada y contestó que en un primer momento forzada por el sultán de Marruecos, que le obligó a abrazar la religión del Profeta en Sigilmasa, si bien cuando pasó a tierras nazaríes volvió voluntariamente al Islam para evitar la esclavitud. Este testimonio parecía más aproximado a la realidad, pues se dudaba seriamente que hubiese permanecido durante los ocho años en que residió en Granada como esclavo. Sus captores entonces le preguntaron directamente si era espía o barrunta al servicio del granadino y si en calidad de tal había acudido a Alicante, a lo que Abdalla respondió que no, manteniendo su hipótesis de que había huido del Islam y se presentaba como cristiano.

No se creyó ni una sola de las palabras pronunciadas por Abdalla, sobre todo su negativa a presentarse como espía, y entonces se ordenó al funcionario encargado del asunto proceder a la tortura del reo al tiempo que se le preguntaba de nuevo per quinya rahó era vengut en lo present loch. Abdalla se derrumbó al dolor así como a la vista del firme propósito de quienes estaban dispuestos a torturarle sin descanso hasta obtener la "verdad esperada" por ellos. Muchas eran las incógnitas no despejadas de su primera declaración, y él lo sabía, así que se decidió a hablar. Por tercera ocasión sus inquisidores oyeron de él decir que diría la veritat.

Se le volvió a preguntar si era espía y si había combatido el lugar y la huerta de Elche junto al resto de enemigos venidos de Granada. Abdalla no tuvo más remedio que reconocer lo segundo -ver fo et cert que talà en la orta de Eltx axí com los altres moros talaven-, pero siguió negando la primera y más grave imputación, la de espionaje. ¿Qué hacía entonces en Alicante? Contestó que había Ilegado a la villa no como espía, ans vench per moro axí como a moro. Con estas declaraciones, lejos de mejorar empeoraba su situación. Abdalla sabía que todas las puertas se le cerrarían si afirmase actuar como espía al servicio del Islam, delito considerado como de lesa majestad que le dirigiría directamente al cadalso para ser decapitado ${ }^{34}$; pero no era

33. Así lo establece la legislación valenciana. Furs e Ordinationts fetes..., Libre IX, rúb. VI, I, p. 159.

34. Ibidem, Libre IX, rúb. IX, I, p. 169. 
capaz de hilvanar una confesión que no dejase tras de sí más sombras que claros. ¿Por qué acudió como musulmán a Alicante? Parecía increíble otra posibilidad que la del espionaje, pues como tal musulmán ya no tenía necesidad de huir. Además, había mostrado un punto débil a sus inquisidores y es la falsedad en alguno de sus testimonios. Ya no se reconocía cristiano, sino musulmán, con lo que nunca quiso volver a ser Andreu Vallés, de Museros, sino Abdalla. La cerrazón en negar su condición de espía por miedo a las consecuencias, sin aclarar de modo convincente cualquier otra razón de su presencia en el reino de Valencia, que como granadino extranjero era considerada ilegal al no presentar licencia de la autoridad correspondiente, hizo que Abdalla reconociese sin quererlo un pecado quizá mayor, la apostasía. Reconocerse en el Islam, habiendo nacido cristiano, renegado de Cristo por propia voluntad, y ser capturado en calidad de tal era desde luego más grave que el espionaje. Lo uno era una falta terrenal, lo otro la condenación eterna. Y todo ello en Semana Santa.

A juicio de Pere Sepulcre el cautivo mentía en el asunto del espionaje, per ço lo dit justícia, per ne lo saber de la bocha de aquell la veritat del feyt, liurà a aquell a questió de turment ab peces de mig quintar. Et estant alt al dit turment fo interrogat de dir veritat del feyt, lo qual respós que'l devallassen et all diría ... tota veritat per quinya rahó era vengut en lo present loch. Su inculpación era cuestión de tiempo. El justicia ordenó que se descolgase al reo y entonces se le volvió a preguntar sobre su presencia en Alicante. Ya no fueron necesarios más castigos corporales. Abdalla se supo vencido y declaró lo que sus captores tanto querían oír. Se confesó musulmán al servicio de Ridwan, caudillo de la hueste granadina que asediaba Elche. Se confesó asimismo espía de Ridwan y justificó su presencia en Alicante en calidad de tal. Explicó que Ridwan le había enviado per espía et barrunta a esa población para conocer su situación defensiva, con qué gentes contaba y sobre todo cuál era el lugar más idóneo para atacarles. Su misión no acababa ahí, debía continuar viaje hacia la huerta de Alicante, poblada por mudéjares, y de ahí hacia la zona de la Marina, que denomina $d^{\prime} E n$ Sarrià -en clara alusión a su señor, Bernat de Sarrià-, et lochs on moros estiguessen hasta el Júcar. Había de presentarse secretamente ante las aljamas y los alamines para rendirles saludos de Ridwan e informarles de que al no haber vencido la resistencia de la villa de Elche el caudillo granadino no continuaría camino hacia el norte. No obstante, pediría a las comunidades musulmanes de la lugartenencia setabense que no desesperasen, pues a pesar de que tras el fracaso ilicitano la hueste retrocedía por las tierras de la Procuración de Orihuela hacia el sur con el botín conseguido, sólo lo harían para acopiar víveres y hombres y preparar una nueva entrada, más poderosa que la anterior, al reino de Valencia por tierra y por mar después de la Cuaresma. Su mensaje a los mudéjares valencianos era que se pertrechasen bien de alimentos -civaba et de pa et de refrescament-y desde dentro realizasen una labor de zapa contra el enemigo cristiano para que cuando los ejércitos nazaries allí llegasen pudiesen ser tomadas fácilmente las fortalezas. 
Una vez realizada esta incursión de castigo, Ridwan prometía llevarse consigo a Granada a los todos los pobladores mudéjares de la montaña alicantina, como decía había hecho con los de Elche y Crevillente.

Es de imaginar el horror y la ira contenida de quienes escucharon estas palabras pronunciadas por el renegado, y no ya sólo porque la propia Alicante, parecía, estaba al alcance del enemigo, sino porque buena parte del reino de Valencia era susceptible de verse atacada. La estrategia granadina, como había sido costumbre y lo seguiría siendo, fue utilizar a la población musulmana residente en Valencia como primer elemento de desequilibrio. Es así que Abdalla reconociese que los propios mudéjares de esta tierra y un renegado, que imaginamos igualmente valenciano, le habían hecho saber que si se dirigía hacia la zona del Júcar, entró a les partes de Xàtiva, podría discurrir por todo el territorio salvo y seguro portando el salvoconducto recibido de Ridwan. Que los mudéjares valencianos estaban conectados con el poder granadino no es ya sólo indiscutible, antes bien, desde luego, tal relación constituía uno de los pilares sobre los que se asentaba la estratregia militar nazarí contra la Corona de Aragón, similar, por otro lado a lo que debiera ocurrir en aquellas comunidades islámicas castellanas situadas por debajo de Despeñaperros y en tierras murcianas ${ }^{35}$.

Todo había sido desvelado. Una vez confeso y culpable el renegado Abdalla, a la pregunta de si otros como él estaban en esos instantes prestando servicios a Granada en aquesta terra, contestó que sí, que además de él ejercían de espías cuatro hombres, tres renegados y un cristiano de Lorca asalariado del Islam. Era un hecho bastante normal que el renegado pasase a prestar servicios militares en defensa de su nueva fe ${ }^{36}$. Fue igualmente preguntado sobre si había sido desarrollado un sistema de comunicacion entre los musulmanes valencianos y los granadinos a fin de que los primeros pudiesen comunicar a sus correligionarios el momento más propicio de su entrada. Declaró que sí, que en la sierra de Tagorina debían hacerse señales de fuego del mismo modo que se hicieron cuando la hueste que había asediado Elche pasó por la Font de la Figuera.

Se le preguntó si venía con la intención expresa de comunicar con alguna persona en concreto y señaló que no. Abdalla debía comunicar con los alamines y con las aljamas que pudiese en ese corto tiempo, señalando siempre que ellos mismos harían correr la especie al resto de las comunidades. Las autoridades cristianas esperaban que Abdalla fuese portador de alguna misiva de Ridwan o incluso del soberano nazarí donde se explicase todo eso con detalle a los alamines y aljamas valencianas, pero el cautivo les desilusionó al declarar que no portaba documento alguno para evitar, precisa-

35. J. TORRES FONTES, «La actividad bélica granadina...»», p. 736.

36. B. BENNASSAR, «La vida de los renegados...», p. 674. 
mente, que el tema no fos descubert ni sabut. De todos modos, el hecho de no llevar certificación escrita de la misión, declaró Abdalla, no era óbice para que no se le reconociese como enviado granadino, pues, según señaló, los mudéjares valencianos aceptarían su palabra per senyals dels oficials et maiorals de la casa del rey de Granada que devía nomenar als dits alamins. Sigue mostrándose nítida la conexión entre unos y otros. La pregunta era obligada ¿qué oficiales eran esos? Abdalla contestó presentando a los cuatro individuos cuyos nombres no podemos leer al completo, muy a nuestro pesar, por mostrarse el documento roto en esa parte. Uno, de nombre Cadí Algenís, sería mayordomo, un segundo se llamaba Farut, un tercero Fer Alcaguer, de Vilajoyosa, y el último Alcayt ¿Yçan?, los quals, decía Abdalla, son officials et maiorals de casa del rey de Granada et aquets tenen tota la casa del dit rey de Granada en poder. Estos cuatro nombres son los que Ridwan dio a nuestro personaje para que los refiriese ante sus interlocutores como contraseña, hecho que a juicio del caudillo tant complia como si portàs letres.

Terminaba Abdalla su preocupante declaración señalando que había sido tratado previamente entre Ridwan y los mudéjares valencianos que en el caso de que el granadino hubiese podido tomar Elche éstos hubiesen colaborado con él para conquistar todos los castillos de la zona en nombre del Islam. La presencia de Abdalla en Alicante y su frustrada visita a tierras de la Marina iba en esa dirección. Acción, decía Abdalla, que de haber cumplido con éxito según fue diseñada, hubiese culminado con su viaje de regreso a Granada al lado de su señor Ridwan; camino de vuelta que hubiese hecho como cristiano.

\section{ALGUNAS CONSIDERACIONES AL RESPECTO}

Del documento se desprenden una serie de datos curiosos sobre los que necesariamente tenemos que reflexionar cara a un mejor entendimiento, no ya tanto de la figura de los renegados, sino antes incluso de aspectos puntuales tocantes al papel jugado por el elemento mudéjar valenciano en las “relaciones" entre la Corona de Aragón y Granada, hasta ahora poco conocidos.

Una primera reflexión, creemos, habrá de girar en torno a la salida de Museros del entonces todavía Andreu Vallés. ¿Qué motivos le hicieron marchar a "tierra de moros"? ¿Lo hizo libremente o movido por las circunstancias? Nada de esto indica Abdalla en sus declaraciones al justicia alicantino. Pero en ese nada se dejan entrever ciertos resquicios que nos permiten, al menos, lanzar alguna hipótesis al respecto. Abdalla no explica en ningún momento la razón de su marcha, sí que lo hizo en compañía de otro cristiano, Ramón Mirambell. Mucho se puede especular con ello. Quizá no lo hiciese por no poder justificarlo. Lo cierto y verdad es que su presencia en tierras africanas sólo podía haberse producido bajo dos formas: voluntaria o forzada. De haber decidido marchar voluntariamente al Islam difícilmente encon- 
traría posibilidad de perdón; sí, en cambio, si fuese de otro modo, es decir, si hubiese sido raptado en tierra o en el mar por piratas magrebíes que lo hubiesen llevado a Fez para ser vendido. Esto último sabemos que no ocurrió, puesto que en su declaración el detenido indica que al menos durante año y medio vivió libremente en Fez y Tremecén en compañía de cristianos. Da entonces la sensación que hubiese decidido viajar de forma voluntaria a esas nuevas tierras ¿en busca de qué? Quizá de aventuras o de fortuna, aunque quizá también movido por alguna circunstancia -huyendo de la justicia o por cualquier otro motivo similar-. Parece menos posible que lo pudiese haber hecho por un convencimiento religioso. En todo ello nada nos puede ayudar el conocimiento que tenemos de la persona. Desconocemos su situación social y económica, la de su familia. No sabemos la profesión de su padre, En Domingo Vallés, ni podemos presuponer que porque se indique el tratamiento de En gozase de una categoría determinada. Es posible que, como en el caso del manchego Juan Rodelgas referido por Bennassar ${ }^{37}$, se tratase de una familia de labradores "modestamente acomodados" en la que uno de los hijos, Andreu, se sintiese más tentado por la aventura que por el trabajo del campo. Un Andreu joven, de eso no deben quedar dudas, que acompañado por Ramón Mirambell, quien quizá le animase a emprender esa aventura o quizá compartiese con él la misma inquietud, pasó a África, directamente a $\mathrm{Fez}$, ciudad, por otro lado, donde residieron gran número de renegados ${ }^{38} . M$. ${ }^{\text {T}}$. Ferrer refiere que durante la primera mitad del siglo XIV la emigración de musulmanes valencianos a países islámicos estuvo permitida por las autoridades cristianas, lógicamente tras salvar los derechos pertinentes, y que incluso resultaba más factible viajar al norte de África que hacerlo a Granada ${ }^{39}$, con lo que no parecía una empresa imposible. Fez podía ser un destino adecuado, pues contaba con una nutrida colonia de cristianos, muchos de ellos mercaderes. La presencia de cristianos en todo el norte de África está más que contrastada ${ }^{40}$.

Otro aspecto sobre el que cabe reflexionar es el importante papel, perdónesenos la insistencia, que en la estrategia militar nazarí jugaban las aljamas valencianas. Siguiendo el relato de Abdalla se entiende que los mudéjares del país estaban perfectamente informados, desde luego mucho mejor que las autoridades cristianas, de todo lo que acontecía en Granada tocante a estas tierras y viceversa. Parece claro que existían unos canales de información muy fluidos entre el estado nazarí y las comunidades musulmanas va-

37. B. Bennassar y L. Bennassar, Los cristianos de Alá..., pp. 29-43.

38. B. BENNASSAR, «La vida de los renegados...», p. 665.

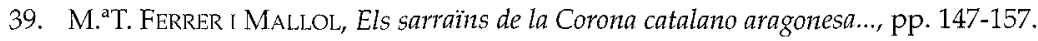

40. M. ${ }^{a}$ D. Lopez Perez, La Corona de Aragón y el Magreb en el siglo XIV (1331-1410), Barcelona, 1995, pp. 130-135. 
lencianas, al menos con las situadas entre el Júcar y la frontera con Murcia. Desde luego el sistema de espionaje granadino en el reino de Valencia debió dar muy buenos resultados, mucho mejores que los de la Corona de Aragón en Granada, pues en el primero de los casos además de los espías y renegados, ambos en número elevado, el estado nazarí contó con las valiosas informaciones facilitadas por un confidente interno, las aljamas valencianas, por los propios musulmanes del país, conocedores como nadie de la geografía, de los movimientos de tropas, del estado de las fortificaciones y de la situación en general de cada uno de los espacios del reino sobre los que los granadinos mostrasen interés; noticias todas ellas que llegarian a sus destinatarios trasladadas personalmente por los correos espías así como a través de sistemas de comunicación de señales visuales. Estos hechos dan todavía mayor validez a las opiniones de Zurita, quien no dudaba de la existencia de tal conexión, refiriéndola con unas preocupantes palabras:

"Y lo que ponía mayor espanto, que los moros de los valles de Riquote y de Elda y Novelda y de los lugares de Elche y Crevillén y universalmente todos los del reino de Valencia solicitaban cada día al rey de Granada que fuese con su poder con muy grandes ofertas que le entregarian a Alicante y a Elche y Crevillen y la Muela con el val de Elda y que se alzarian todas las aljamas" $^{\prime \prime 1}$.

En el caso que nos ocupa queda patente que los mudéjares de la Marina conocían perfectamente la llegada de Ridwan esa primavera al frente de una tropa; que su objetivo primero sería Elche; y que de haberse conseguido eran las tierras de la lugartenencia ultra Xucarum las que se habrían visto invadidas. Pero además algo más. Esta entrada granadina no fue sólo una razzia fronteriza para conseguir botín y demostrar al rey de Aragón el poder de destrucción de los ejércitos de la media luna; creemos que estaba dentro de una estrategia hábilmente tejida por los granadinos para devastar y despoblar de sarracenos la mitad sur del reino de Valencia. Éste es el propósito que Abdalla confiesa y para el cual estaban movilizadas todas las aljamas situadas entre Alicante y Xàtiva. Si esto es así, puede ser que el ataque que el mismo Ridwan realizó en octubre de 1331 sobre Guardamar y que le repercutió tan pingües beneficios en cautivos, reses y población musulmana que de forma voluntaria marchó con él a Granada, hubiese sido un ensayo para comprobar si la estrategia a desplegar era la idónea, el grado de dificultad de la empresa y el valor y la fiabilidad de la colaboración de sus correligionarios valencianos. El éxito del ataque a Guardamar, aunque matizado por las facilidades que ofrecian las limitadas defensas del lugar, pero sobre todo la buena acogida que tuvo entre los mudéjares de la Procuración de Orihuela, debió ser el indicador que haría posible esta segunda tentativa escasos meses después.

41. J. de Zurria, Anales..., 3, VII, XV, pp. 348-349. 
Con una planificación excelente, Ridwan y su ejército pusieron en tela de juicio los servicios de inteligencia de Alfonso el Benigno al no ser detectados prácticamente hasta llegar a las puertas de Elche; ello pese a saberse de tiempo atrás por las declaraciones de algunos espías renegados capturados que los granadinos preparaban otra incursión a las tierras de la Procuración de Orihuela y que contaban con el apoyo de las aljamas del territorio ${ }^{42}$. Previo a los ataques de 1331 y de 1332 Granada habría puesto en marcha su aparato propagandístico dentro del reino de Valencia, no ya para lograr la connivencia de sus pobladores musulmanes -contaba con ella desde época de la conquista-, sino fundamentalmente para tratar de convencerles a fin de que abandonasen sus hogares y viajar hasta Granada. Les presentarían las excelencias de una vida plenamente islámica así como las facilidades del viaje; naves nazaríes fondeadas en las costas estarían esperando a los pasajeros para trasladarlos seguramente hasta Almería.

El plan se vino abajo cuando Elche resistió el asedio de Ridwan. Posiblemente calculó mal sus fuerzas o subestimó las de los ilicitanos, hombres y mujeres que apostados en las murallas se defendieron heroicamente ${ }^{43}$. Quizá la confianza le jugó una mala pasada. Lo cierto es que este fracaso impidió la ejecución de lo planificado. Tras cinco días de asedio, del 9 al 14 de abril, los invasores se dedicaron a destruir aquello que pudieron durante los días siguientes antes de regresar a Granada. Zurita refiere que el abandono del cerco de Elche por parte de los granadinos se debió a las noticias que hasta allí llegaron relativas a la presencia del rey de Aragón al frente de una hueste que se dirigía hacia el sur, hecho que según M. ${ }^{2}$ T. Ferrer, independientemente del número de sus componentes, la convertía en un "exèrcit temible". Desde luego ambas aseveraciones son plenamente acertadas, pero a la luz de lo declarado por Abdalla sería lógico pensar que el caudillo nazarí esperase una reacción semejante por parte de Alfonso el Benigno. Pensamos que todo eso estaba calculado, si bien sujeto a unas muy precisas coordenadas temporales que se vieron quebradas con la resistencia no esperada de Elche.

Fue precisamente el último día de asedio a la plaza, martes, cuando el caudillo granadino envió al renegado Abdalla para visitar a las comunidades mudéjares que esperaban a sus libertadores y referirles la imposibilidad de su presencia en ese momento. Si bien, la idea originaria seguía vigente, pues el mensajero les comunicaría que ésta quedaba pospuesta para dar tiempo al ejército de Ridwan a descansar y abastecerse para, pasada la Cuaresma, vol-

42. M.'T. FerRer i MALLOL, La frontera amb l'Islam..., p. 129.

43. J. Zurira, Anales..., 3, VII, XVIII. J. Hinojosa MonTalvo, Crónica de Pero Maça, edición, intro-

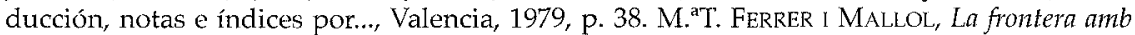
I'Tslam..., p. 134. 
ver a Valencia por tierra y por mar, destruir las fortalezas con el apoyo de la quinta columna de musulmanes del país y regresar a Granada en compañía de éstos.

No sabemos cómo había calado la idea de marchar a Granada entre los mudéjares valencianos. Es posible que en principio les resultase muy atractiva, aun con el consiguiente pesar de verse en la obligación de abandonar la tierra en la que habían vivido desde siglos atrás. Lo que sí conocemos es que en muy pocos casos Granada resultó ser la panacea para los huidos, hasta el punto que muchos de aquellos que marcharon voluntariamente con Ridwan en la entrada de octubre de 1331, como sucediese a los mudéjares de la Daya y de Elche, a los escasamente dos meses pretendían volver a sus lugares de origen $^{44}$. El camino de ida y vuelta hacia tierras nazaríes fue emprendido en innumerables ocasiones por los musulmanes habitantes en el reino de Valencia, personas individuales, familias e incluso comunidades enteras: "La determinació d'abandonar terres, cases i béns fou presa en un moment d'exaltació religiosa; els sarraïns degueren dir-se que ja n'hi havia prou de viure sota el jou cristià i que més valia abandonar-ho tot i viure amb els germans de religió sota la llei islàmica" ${ }^{\prime 5}$. Este texto, con el que M. ${ }^{a}$ T. Ferrer explica las motivaciones de la marcha de algunos musulmanes con el grupo del magrebí al-Abbas Ibn Rahu en 1304, es perfectamente extrapolable a cualesquiera otras huidas. Cuando no era la presencia física en la zona de algún caudillo, como el citado Ibn Rahu o Ridwan, serían los predicadores o los espías los encargados de mantener viva la llama de la fuga. Pero lo cierto es que en muchos casos la experiencia granadina resultó traumática para los expedicionarios, hasta el punto de que en más de una ocasión eran los propios huidos quienes solicitaban a los reyes catalano-aragoneses licencia especial para regresar a sus casas, a tenor de su marcha ilegal, o incluso regresaban sin contar con ella, tal y como la citada autora y el autor de estas páginas han puesto de manifiesto ${ }^{46}$.

\section{RESUMEN}

En este trabajo pretendemos mostrar la historia singular -en cuanto a única y personal - de la peripecia vital de un cristiano valenciano que a mediados de la segunda década del siglo XIV, en un mundo -su propia tierra- de marcado fervor antiislámico, abandonó la seguridad de su casa, de su familia, para, consciente o inconscientemente, vivir una aventura que, seguramente, le

44. M. ${ }^{a}$ T. FERRER I MALLOL, La frontera amb l'Tslam..., p. 129 y doc. n. ${ }^{0} 57$.

45. Ibidem, p. 88.

46. J.V. Cabezuelo Plego, Poder público y administración territorial... 
terminó reportando una muerte cruel. Es el caso de Abdalla/Andreu, fill d'En Domingo Vallés, cristiano de Alá, renegado de Cristo.

\section{ABSTRACT}

In this article we have the intention of telling the peculiar story -for its unique and personal characteristics- and the ups and downs of a Valencian Christian who, in the middle of the second decade of the 14th Century, abandoned his family and home security to live an adventure which certainly, conscious or unconsciously, was going to cause his cruel death. This is the story of Abdalla-Andreu, son of En Domingo Vallés, a Christian of Allah, a renegade Christian. 